\title{
Proactive coping poststroke: psychometric properties of the Utrecht proactive coping competence scale
}

Citation for published version (APA):

Tielemans, N. S., Visser-Meily, J. M. A., Schepers, V. P., Post, M. W. M., \& van Heugten, C. M. (2014). Proactive coping poststroke: psychometric properties of the Utrecht proactive coping competence scale. Archives of Physical Medicine and Rehabilitation, 95(4), 670-675.

https://doi.org/10.1016/j.apmr.2013.11.010

Document status and date:

Published: 01/01/2014

DOI:

10.1016/j.apmr.2013.11.010

Document Version:

Publisher's PDF, also known as Version of record

Document license:

Taverne

\section{Please check the document version of this publication:}

- A submitted manuscript is the version of the article upon submission and before peer-review. There can be important differences between the submitted version and the official published version of record.

People interested in the research are advised to contact the author for the final version of the publication, or visit the DOI to the publisher's website.

- The final author version and the galley proof are versions of the publication after peer review.

- The final published version features the final layout of the paper including the volume, issue and page numbers.

Link to publication

\footnotetext{
General rights rights.

- You may freely distribute the URL identifying the publication in the public portal. please follow below link for the End User Agreement:

www.umlib.nl/taverne-license

Take down policy

If you believe that this document breaches copyright please contact us at:

repository@maastrichtuniversity.nl

providing details and we will investigate your claim.
}

Copyright and moral rights for the publications made accessible in the public portal are retained by the authors and/or other copyright owners and it is a condition of accessing publications that users recognise and abide by the legal requirements associated with these

- Users may download and print one copy of any publication from the public portal for the purpose of private study or research.

- You may not further distribute the material or use it for any profit-making activity or commercial gain

If the publication is distributed under the terms of Article $25 \mathrm{fa}$ of the Dutch Copyright Act, indicated by the "Taverne" license above, 


\title{
Proactive Coping Poststroke: Psychometric Properties of the Utrecht Proactive Coping Competence Scale
}

\author{
Nienke S. Tielemans, MSc, ${ }^{a, b}$ Johanna M. Visser-Meily, MD, PhD, ${ }^{b}$ \\ Vera P. Schepers, MD, PhD, ${ }^{b}$ Marcel W. Post, $\mathrm{PhD}^{b}$ Caroline M. van Heugten, $\mathrm{PhD}^{\mathrm{a}, \mathrm{c}}$ \\ From the ${ }^{a}$ Department of Psychiatry and Neuropsychology, Maastricht University Medical Centre, Maastricht; ${ }^{b}$ Brain Center Rudolf Magnus and \\ Center of Excellence for Rehabilitation Medicine, University Medical Center Utrecht and Rehabilitation Center De Hoogstraat, Utrecht; and \\ ${ }^{c}$ Department of Neuropsychology and Psychopharmacology, Maastricht University, Maastricht, The Netherlands.
}

\begin{abstract}
Objective: To examine psychometric properties of the Utrecht Proactive Coping Competence scale (UPCC) and explore relations of proactive coping with health-related quality of life (HRQOL) and characteristics of patients with stroke.

Design: Cross-sectional study. Reliability and convergent validity, and associations with HRQOL and characteristics of patients with stroke were examined.

Setting: Inpatient and outpatient settings of hospitals and rehabilitation centers in The Netherlands.

Participants: Patients with stroke $(\mathrm{N}=55$; mean age, $58.7 \pm 12.8 \mathrm{y}$; mean months since stroke, $25.0 \pm 38.5)$.

Interventions: Not applicable.

Main Outcome Measures: UPCC, Utrecht Coping List (UCL), and the short Stroke Specific Quality of Life scale (SS-QOL-12).

Results: The UPCC showed excellent reliability (Cronbach's $\alpha=.95$ ) without floor/ceiling effects or skewed score distribution. Convergent validity was shown by moderate positive relations with the UCL subscale active problem solving $(r=.38)$ and moderate negative relations with the UCL subscales passive reactions $(r=-.50)$, avoidance $(r=-.40)$, and expression of emotions $(r=-.42)$. Correlations between the UPCC and HRQOL domains were moderate to strong $(r=.48-.61)$ and stronger than those between UCL subscales and HRQOL domains. The only characteristic of patients with stroke associated with proactive coping was time after stroke $(r=-.52)$.

Conclusions: The UPCC appears reliable and valid for patients with stroke. Moreover, we found positive associations between proactive coping and HRQOL. Future research is recommended to confirm our results and to explore ways to enhance proactive coping in patients with stroke. Archives of Physical Medicine and Rehabilitation 2014;95:670-5
\end{abstract}

(C) 2014 by the American Congress of Rehabilitation Medicine

The coming years are expected to show a considerable increase in the number of people surviving a stroke, due to decreasing case fatality and the aging population. ${ }^{1,2}$ Patients with stroke often report reduced health-related quality of life (HRQOL), ${ }^{3,4}$ and many have to adjust their lives to the lasting consequences of stroke. Important determinants in this adjustment process after stroke are coping strategies, that is, the emotional, cognitive, and behavioral strategies people use to deal with the consequences of

Presented to the Special Interest Group of the World Federation for NeuroRehabilitation, July 8-9, 2013, Maastricht, The Netherlands.

Supported by the Dutch VSBFonds (grant no. 89000004) and the Dutch Heart Foundation. The funding sources had no involvement in the study design; in the collection, analysis, and interpretation of data; in the writing of the report; and in the decision to submit the article for publication.

No commercial party having a direct financial interest in the results of the research supporting this article has conferred or will confer a benefit on the authors or on any organization with which the authors are associated. stroke. $^{3,5-9}$ Traditionally, these strategies are dichotomized as problem-based coping strategies or emotion-based coping strategies. ${ }^{8}$ Problem-based coping strategies are strategies adopted to change the situation, while emotion-based coping strategies aim at handling the emotions resulting from the situation. ${ }^{8}$ Few studies have investigated the relation between coping strategies and poststroke HRQOL, though a study reported positive relations between problem-based coping strategies and long-term HRQOL in a sample of patients with acquired brain injury.

Most coping studies have evaluated coping with situations that have already occurred (ie, reactive coping). ${ }^{10,11}$ Less attention has been paid to proactive coping strategies, that is, people's attempts to anticipate the occurrence of potential negative consequences of stroke before undertaking an activity to deal with these consequences as effectively as possible. Proactive coping is expected to 
result in better adjustment to chronic conditions such as stroke because it enables patients to prevent and prepare for restrictive consequences of the condition in advance. ${ }^{10}$ Research in elderly people and people with type 2 diabetes has supported this idea because proactive coping strategies were associated with a better ability to deal with the consequences of a condition and with realistic goal setting and achievement. ${ }^{12,13}$

Many stroke-specific education and self-management interventions aim to teach participants strategies to deal with the consequences of stroke. ${ }^{14,15}$ In our opinion, these interventions should focus on teaching proactive coping strategies. This requires instruments to assess a participant's level of proactive coping strategies in order to determine intervention goals and effectiveness, but such instruments with good psychometric properties are lacking for patients with stroke. Research in other populations suggests that the Utrecht Proactive Coping Competence scale (UPCC) is a promising instrument. ${ }^{12,13,16}$

The aim of this study was therefore to evaluate the psychometric properties of the UPCC in patients with stroke. In combination with studying the associations of proactive coping with patients' characteristics and HRQOL, this is expected to provide a first exploration of this concept in patients with stroke.

\section{Methods}

\section{Participants}

People with stroke were recruited from both inpatient and outpatient settings of the University Medical Centre Utrecht, Utrecht; St Antonius Hospital, Nieuwegein; De Hoogstraat Rehabilitation, Utrecht; and Rehabilitation Centre Via Reva, Deventer, all located in The Netherlands, between January and August 2011. People were eligible if they (1) had suffered a first or recurrent stroke (ie, have had $\geq 2$ strokes) and (2) were aged 18 years or older. The exclusion criterion was inability to complete the questionnaire because of (1) cognitive impairment or (2) communicative impairment (score $<5$ on the shortened version of the Aphasia Scale of the Dutch Aphasia Foundation). ${ }^{17}$ These criteria were clinically assessed by the attending rehabilitation physician.

\section{Procedure}

People with stroke were informed about the study by their rehabilitation physician at their regular visit to the inpatient or outpatient service of the participating hospitals and rehabilitation centers. If interested, they received an information letter together with the study questionnaire. They were asked to complete the questionnaire at home and return it to the researchers by mail in an enclosed envelope if they consented to participate in the study. In addition, they gave permission for using the data on their stroke characteristics to be provided by their rehabilitation physician. The study protocol was approved by the local medical research ethics committees of the participating hospitals and rehabilitation centers.

\section{List of abbreviations: \\ HRQOL health-related quality of life \\ SS-QOL-12 Short Stroke-Specific Quality of Life scale \\ UCL Utrecht Coping List \\ UPCC Utrecht Proactive Coping Competence scale}

\section{Measures}

The rehabilitation physician provided data about stroke characteristics in terms of stroke-affected hemisphere, time since stroke, type of stroke, stroke history, and independence in activities of daily living (Barthel index score, 0-20). ${ }^{18}$ The study questionnaire consisted of the UPCC, ${ }^{12,16}$ the Utrecht Coping List (UCL), ${ }^{19}$ the Short Stroke-Specific Quality of Life scale (SSQOL-12), ${ }^{20}$ and questions on demographic characteristics (ie, age, sex, educational level, marital status, employment status).

The UPCC measures self-rated proactive coping competencies. A total of 21 items are assessed on a 4-point scale, with anchors ranging from "not competent at all" to "very competent." Examples of questions are as follows: "To what extent do you have the capacity to make realistic plans?" and "To what extent do you have the capacity to persist?" Total scores are calculated by averaging the individual item scores. Higher scores on the UPCC indicate higher levels of perceived proactive coping competencies. ${ }^{16}$ The updated English and Dutch versions of the UPCC are available on http://selfregulationlab.nl/questionnaires/. In earlier studies, this instrument was also called the Proactive Competence Scale. ${ }^{12}$ The UPCC has shown good internal consistency (Cronbach's $\alpha=.83-.95$ ), test-retest reliability ( $r=.45-$ .82 ), and sensitivity to changes after education interventions in healthy young people (aged 18-35y), people in late adulthood (aged 50-75y), and people diagnosed with type 2 diabetes. $^{16}$

The UCL is a self-report measure of 7 coping styles: passive reactions ( 7 items), active problem solving (7 items), palliative reactions (8 items), seeking social support (6 items), avoidance (8 items), expression of emotions ( 3 items), and reassuring thoughts (5 items). ${ }^{19}$ Items are assessed on a 4-point scale, with anchors ranging from "seldom" to "very often." Total scores for each subscale are calculated by adding up the individual item scores belonging to the particular subscale. Higher scores on the scales indicate a greater tendency to adopt that particular coping style. The UCL is frequently applied in Dutch clinical practice and has been used in several earlier studies among people with stroke or other types of brain injury. ${ }^{9,21}$ Studies among several Dutch samples found that the UCL showed moderate to good internal consistency (Cronbach's $\alpha=.43-.89$ ) and test-retest reliability $(r=.37-.85){ }^{19}$

The SS-QOL-12 measures self-rated HRQOL. Six items represent physical HRQOL, and 6 items represent psychosocial HRQOL. Items are assessed on either a 5-point scale with anchors ranging from "not able at all" to "no trouble at all" or a 5-point scale with anchors ranging from "strongly agree" to "strongly disagree." Domain scores and total scores are calculated by averaging the individual item scores. Higher scores indicate a better HRQOL. The SS-QOL-12 showed good internal consistency (Cronbach's $\alpha=.77-.89$ ) and predicted $88 \%$ to $95 \%$ of the variance of the original Short Stroke-Specific Quality of Life scale in studies among people with stroke. ${ }^{20}$

\section{Statistical analyses}

Data were analyzed with IBM SPSS Statistics $18 .^{\text {a }}$ Statistics about the score distribution were reported for the UPCC, and subscales of the UCL and the SS-QOL-12, in terms of its mean, $\mathrm{SD}$, median, range, number of missing values, skewness, and floor and ceiling effects. Skewness values lower than -1.0 or higher than 1.0 were regarded as strong, and those between 0.5 and 1.0 and 
-0.5 and -1.0 were regarded as moderate. ${ }^{22}$ Floor and ceiling effects were interpreted as present if at least $15 \%$ of the participants obtained the highest or lowest score. Internal consistency of the UPCC was assessed in terms of Cronbach's alpha $(>0.9=$ excellent; $0.9-0.8=$ good; $0.8-0.7=$ acceptable; $0.7-0.6=$ questionable; $0.6-0.5=$ poor; and $<0.5=$ unacceptable). ${ }^{23}$

Convergent validity was examined by calculating Spearman correlation coefficients between the UPCC scores and the UCL subscales, the SS-QOL-12, and participant characteristics. Correlations were interpreted as strong if higher than 0.6 , moderate between 0.3 and 0.6 , and weak if smaller than $0.3 .^{24}$ Specifically, a positive correlation was expected between the UPCC and the active problem-solving subscale of the UCL. Negative correlations were expected between the UPCC and the emotion-based coping subscales for avoidance, expression of emotions, reassuring thoughts, palliative reactions, seeking social support, and passive reactions of the UCL. Positive correlations were expected between proactive coping strategies and HRQOL poststroke, and we hypothesized that the correlations between the UPCC and the SS-QOL-12 would be stronger than those between the UCL subscales and the SS-QOL-12.

\section{Results}

\section{Participants' characteristics}

A total of 57 people with stroke returned the questionnaires, 55 of whom completed the UPCC, the UCL, and the SS-QOL-12. The characteristics of the participants are presented in table 1. Participants had a mean age of $58.7 \pm 12.8$ years, and the mean time since stroke was $25.0 \pm 38.5$ months. Most participants $(n=47)$ were independent in basic activities of daily living reflected by a Barthel index score of $20 .{ }^{25}$ The mean Barthel index score was $19.7 \pm 1.2$.

\section{Score distribution and reliability}

Table 2 presents the score distributions of the UPCC and of the subscales of the UCL and the SS-QOL-12.

Overall, for the UPCC, $0.9 \%$ of the items were missing, no floor or ceiling effects were detected, and the skewness values were acceptable. The internal consistency of the UPCC score was excellent (Cronbach's $\alpha=.95$ ).

\begin{tabular}{ll} 
Table $1 \quad$ Participants' characteristics $(\mathrm{n}=55)$ & \\
\hline Characteristic & Values \\
\hline Demographic characteristics & \\
Sex: male & $28(50.9)$ \\
Age $(\mathrm{y})$ & $58.7 \pm 12.8$ \\
Educational level: at least secondary school & $50(90.9)$ \\
Marital status: living with partner & $40(72.7)$ \\
Employment status: employed & $29(52.7)$ \\
Stroke characteristics & \\
Time after stroke (mo) & $25.0 \pm 38.5$ \\
Type of stroke: infarction & $45(81.8)$ \\
Affected hemisphere: left & $26(47.3)$ \\
Stroke history: recurrent & $11(20.0)$ \\
Barthel index score $(0-20)$ & $19.7 \pm 1.2$ \\
\hline
\end{tabular}

NOTE. Values are $n(\%)$ or mean \pm SD.
On average, $1.1 \%$ of the items were missing for the subscales of the UCL and no floor or ceiling effects were detected. The skewness was acceptable for all subscales, although the subscale seeking social support was at the border of what is considered as acceptable (ie, -0.5 ).

On average, $0.3 \%$ of the items were missing for the subscales of the SS-QOL-12, and no floor or ceiling effects were detected at all. Only the subscale measuring the physical domain of HRQOL was moderately skewed (ie, -0.8 ).

\section{Convergent validity of the UPCC}

Table 3 presents correlations of the UPCC with the UCL subscales and participants' characteristics.

There was a moderate positive correlation between the UPCC and the UCL active problem solving subscale $(r=.38 ; P<.01)$. Moderate negative correlations were found between the UPCC and the UCL subscales for passive reactions $(r=-.50 ; P<.01)$, avoidance $(r=-.40 ; P<.05)$, and expression of emotions $(r=-0.42$; $P<.05)$. No significant correlations were found between the UPCC and the UCL subscales for seeking social support, palliative reactions, and reassuring thoughts.

None of the demographic characteristics showed a significant relation with the UPCC scores. Concerning the stroke characteristics, only time after stroke was significantly associated with scores on the UPCC. When time after stroke increased, UPCC scores decreased $(r=-.52 ; P<.01)$.

\section{Proactive coping and HRQOL}

Table 4 presents the correlations between the SS-QOL-12, the UPCC, and the UCL.

A strong positive correlation was found between the UPCC score and the total SS-QOL-12 score. Moderate positive correlations were found between the UPCC and the physical and psychosocial domains of the SS-QOL-12.

The associations between coping strategies measured with the UCL and HRQOL were weaker than those between the UPCC and HRQOL, ranging from $|r|=.23$ to .43 within the physical domain, $|r|=.25$ to .49 within the psychosocial domain, and $|r|=.26$ to .51 within the total domain.

\section{Discussion}

This study demonstrated good psychometric properties of the UPCC in people with stroke in terms of score distribution, reliability, and convergent validity. Having such a measure enables us to further explore the construct of proactive coping in patients with stroke. The moderate to strong correlations between the UPCC and the SS-QOL-12 suggest the relevance of proactive coping strategies for poststroke HRQOL.

The results of this study were similar to those of earlier UPCC studies in other populations. ${ }^{16}$ The internal consistency of the UPCC was outstanding compared with the alpha values of most other coping measures in patients with stroke. ${ }^{26}$ This high internal consistency can be partly explained by the relatively large number of items all measuring the same coping construct, while most other coping questionnaires measure several coping constructs with a smaller number of questions per scale. ${ }^{26}$

The expected negative relations between the UPCC and UCL subscales for palliative reactions, seeking social support, and 


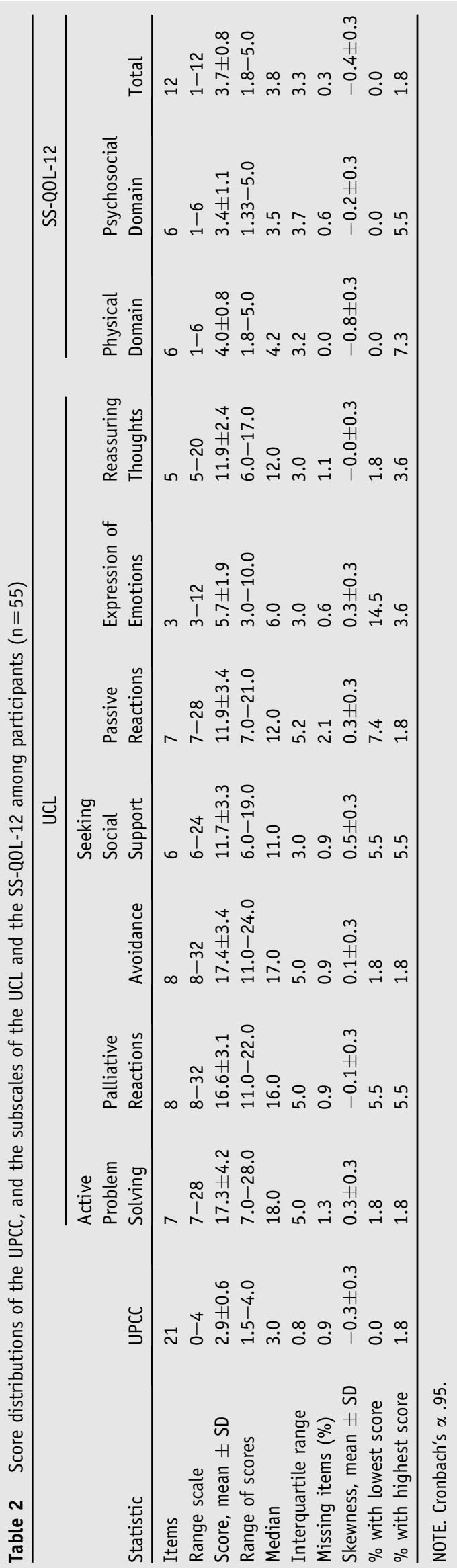

reassuring thoughts failed to appear. However, this is in line with the growing number of researchers proposing that the broad spectrum of coping is not adequately captured by the traditional dichotomy as problem-based or emotion-based coping strategies. As a reaction, several new classifications of coping have been proposed in terms of new subdivisions of coping and classifications at higher order levels $s^{3,19,26,27}$; the concept of proactive coping is one of these new forms.

No association was found between the level of independence in basic activities of daily living and proactive coping strategies. However, this could be the result of the high level of functioning of the surveyed patients with stroke in this study.

The second part of our study supported the proposed positive associations between active problem-based coping strategies and long-term HRQOL. ${ }^{9}$ Although the cross-sectional design of the study means that caution should be exercised in interpreting this result, the associations of HRQOL with proactive coping were stronger than with other coping strategies measured with the UCL. Therefore, our results clearly provide further support for the importance of proactive coping poststroke.

In view of the positive association between proactive coping and HRQOL, it is striking that we found a moderate negative association between proactive coping strategies and time after stroke. However, the cross-sectional nature of our data limits us in making inferences about the nature of this association. Longitudinal research efforts are needed to investigate whether this association reflects an actual reduction in the levels of proactive coping strategies adopted over time or whether other explanations are possible.

This study distinguishes itself from earlier coping studies in patients with stroke in several ways. First, it is the first study to explore proactive coping strategies in patients with stroke. Second, the convergent validity of the UPCC was assessed by exploring associations with measures of other coping strategies instead of determining associations with related variables (such as anxiety or well-being). ${ }^{21}$

Table 3 Associations between the UPCC and the subscales of the UCL and participants' characteristics

\begin{tabular}{lc}
\hline UCL & UPCC \\
\hline Active problem solving & $.38^{*}$ \\
Palliative reactions & .11 \\
Avoidance & $-.40^{*}$ \\
Seeking social support & .16 \\
Passive reactions & $-.50^{*}$ \\
Expression of emotions & $-.42^{*}$ \\
Reassuring thoughts & .02 \\
Demographic characteristics & \\
Sex & -.21 \\
Age & -.06 \\
Educational level & .11 \\
Living with partner & -.22 \\
Employment status & -.11 \\
Stroke characteristics & \\
Time after stroke & $-.52^{*}$ \\
Type of stroke & .02 \\
Stroke-affected hemisphere & -.02 \\
Stroke history & -.01 \\
Functional status (Barthel index score) & .18 \\
\hline * P<.01. & \\
&
\end{tabular}


Table 4 Associations between the SS-Q0L-12 and the UPCC and the subscales of the UCL

\begin{tabular}{lccc}
\hline & \multicolumn{3}{c}{ SS-Q0L-12 } \\
\cline { 2 - 4 } Scale & $\begin{array}{l}\text { Physical } \\
\text { Domain }\end{array}$ & $\begin{array}{l}\text { Psychosocial } \\
\text { Domain }\end{array}$ & Total \\
\hline UPCC & $.48^{*}$ & $.58^{*}$ & $.61^{*}$ \\
UCL & & & \\
$\quad$ Active problem solving & $.33^{*}$ & .20 & $.28^{\dagger}$ \\
Palliative reactions & $-.03^{\dagger}$ & -.12 & -.10 \\
Avoidance & $-.29^{\dagger}$ & $-.45^{*}$ & $-.43^{*}$ \\
Seeking social support & .15 & .13 & .15 \\
Passive reactions & $-.43^{*}$ & $-.49^{*}$ & $-.51^{*}$ \\
Expression of emotions & $-.27^{\dagger}$ & $-.45^{*}$ & $-.42^{*}$ \\
Reassuring thoughts & $-.23^{\dagger}$ & $-.25^{\dagger}$ & $-.26^{\dagger}$ \\
\hline$* P<.01$. & & & \\
$\dagger$ & & & \\
\hline$P<.05$. & & &
\end{tabular}

\section{Study limitations}

A few critical notes are also in order. First, further research is needed to assess other psychometric properties of the UPCC, such as test-retest reliability and responsiveness, in patients with stroke. Second, although our sample size was sufficient for a clinimetric study, ${ }^{21}$ it was relatively small, which limits the accuracy of our conclusions about the effect of clinical and demographical variables. Therefore, more research is recommended to confirm our results. Finally, it is uncertain whether the outcomes of our study can be generalized to more severely affected groups of patients with stroke than higher functioning patients.

\section{Conclusions}

The UPCC proved to be a reliable and valid measure for use in patients with stroke and thus suitable to assess proactive coping strategies in this diagnostic group. We recommend this coping construct because our findings suggest positive relations of proactive coping with HRQOL.

\section{Supplier}

a. SPSS Inc, 233 S Wacker Dr, 11th Fl, Chicago, IL 60606.

\section{Keywords}

Adaptation, psychological; Psychometrics; Quality of life; Rehabilitation; Stroke

\section{Corresponding author}

Caroline M. van Heugten, $\mathrm{PhD}$, Faculty of Health, Medicine and Life Sciences, Department of Psychiatry and Neuropsychology, Maastricht University, PO Box 616, 6200 MD Maastricht, The Netherlands. E-mail address: c.vanheugten@maastrichtuniversity.nl.

\section{References}

1. Sarti C, Stegmayr B, Tolonen H, Mahonen M, Tuomilehto J, Asplund K. Are changes in mortality from stroke caused by changes in stroke event rates or case fatality? Results from the WHO MONICA project. Stroke 2003;34:1833-40.

2. United Nations. World population ageing 2009. New York: United Nations; 2009.

3. Darlington AS, Dippel DW, Ribbers GM, van Balen R, Passchier J, Busschbach JJ. A prospective study on coping strategies and quality of life in patients after stroke, assessing prognostic relationships and estimates of cost-effectiveness. J Rehabil Med 2009;41:237-41.

4. Haley WE, Roth DL, Kissela B, Perkins M, Howard G. Quality of life after stroke: a prospective longitudinal study. Qual Life Res 2011;20: 799-806.

5. Rochette A, Bravo G, Desrosiers J, St-Cyr Tribble D, Bourget A. Adaptation process, participation and depression over six months in first-stroke individuals and spouses. Clin Rehabil 2007;21:554-62.

6. Lazarus RS, Folkman S. Stress, appraisal and coping. New York: Springer; 1984.

7. Darlington AS, Dippel DW, Ribbers GM, van Balen R, Passchier J, Busschbach JJ. Coping strategies as determinants of quality of life in stroke patients: a longitudinal study. Cerebrovasc Dis 2007;23: 401-7.

8. Folkman S, Lazarus RS. An analysis of coping in a middle-aged community sample. J Health Soc Behav 1980;21:219-39.

9. Wolters G, Stapert S, Brands I, Van Heugten C. Coping styles in relation to cognitive rehabilitation and quality of life after brain injury. Neuropsychol Rehabil 2010;20:587-600.

10. Aspinwall LG, Taylor SE. A stitch in time: self-regulation and proactive coping. Psychol Bull 1997;121:417-36.

11. Schwarzer R, Taubert S. Tenacious goal pursuits and striving toward personal growth: proactive coping. In: Frydenberg E, editor. Beyond coping: meeting goals, visions and challenges. London: Oxford Univ Pr; 2002. p 19-35.

12. Bode C, de Ridder DT, Kuijer RG, Bensing JM. Effects of an intervention promoting proactive coping competencies in middle and late adulthood. Gerontologist 2007;47:42-51.

13. Thoolen BJ, de Ridder D, Bensing J, Gorter K, Rutten G. Beyond good intentions: the role of proactive coping in achieving sustained behavioural change in the context of diabetes management. Psychol Health 2009;24:237-54.

14. Foster A, Brown L, Smith J, et al. Information provision for stroke patients and their caregivers. Cochrane Database Syst Rev 2012;11: $1-129$.

15. Lennon S, McKenna S, Jones F. Self-management programmes for people post stroke: a systematic review. Clin Rehabil 2013;27: 867-78.

16. Bode C, Thoolen B, de Ridder D. [Measuring proactive coping. Psychometric characteristics of the Utrecht Proactive Coping Competence scale (UPCC)] [Dutch]. Psychologie Gezondheid 2008; 36:81-91.

17. Visser-Meily A, Meijer R. [Discharge guide: decision tree for discharge destination from hospital for patients after stroke] [Dutch]. Hilversum: Mewadruk; 2010.

18. Collin C, Wade DT, Davies S, Horne V. The Barthel ADL index: a reliability study. Int Disabil Stud 1988;10:61-3.

19. Schreurs PJG, Van de Willege G, Brosschot JF, Tellegen B, Graus GMH. [The Utrechtse coping list: UCL manual] [Dutch]. Utrecht: Swets en Zeitlinger; 1993.

20. Post MW, Boosman H, van Zandvoort MM, Passier PE, Rinkel GJ, Visser-Meily JM. Development and validation of a short version of the Stroke Specific Quality of Life Scale. J Neurol Neurosurg Psychiatry 2011;82:283-6.

21. Aben L, Busschbach JJ, Ponds RW, Ribbers GM. Memory selfefficacy and psychosocial factors in stroke. J Rehabil Med 2008;40:681-3. 
22. Bulmer MG. Principles of statistics. New York: Dover Publications, Inc; 1979.

23. Terwee CB, Bot SDM, de Boer MR, et al. Quality criteria were proposed for measurement properties of health status questionnaires. J Clin Epidemiol 2007;60:1-104.

24. Visser-Meily J, Post M, Riphagen I, Lindeman E. Measures used to assess burden among caregivers of stroke patients: a review. Clin Rehabil 2004;18:601-23.
25. Wade DT, Hewer RL. Functional abilities after stroke: measurement, natural history and prognosis. J Neurol Neurosurg Psychiatry 1987;50:177-82.

26. Donnellan C, Hevey D, Hickey A, O'Neill D. Defining and quantifying coping strategies after stroke: a review. J Neurol Neurosurg Psychiatry 2006;77:1208-18.

27. Skinner EA, Edge K, Altman J, Sherwood H. Searching for the structure of coping: a review and critique of category systems for classifying ways of coping. Psychol Bull 2003;129:216-69. 